\title{
Decompressive Hemicraniectomy in the Treatment of Malignant Middle Cerebral Artery Infarction
}

\author{
MOHAMED A. GHONEIM, M.D. and HUSSEIN FATHALLA, M.D. \\ The Department of Neurosurgery, Faculty of Medicine, Cairo University
}

\begin{abstract}
Background: Malignant middle cerebral artery infarctions affecting about $10 \%$ of stroke patients. Formed of huge spaceoccupying infarctions with extensive edema which lead to herniation, and usually death. Treatment includes medical treatment in addition to decompressive hemicraniectomy associated with duroplasty in many cases. Decompressive craniectomy has a great effect in reduction of mortality rates and improving the functional outcome of the patients.

Aim of Study: We reviewed the outcome of decompressive hemicraniectomy in the treatment of Malignant Middle Cerebral Artery infarction.

Patients and Methods: The study includes 14 patients of malignant middle cerebral artery infarctions operated upon by decompressive surgery (from January 2015 to August 2018). We evaluated the outcome by estimation of the mortality rate after one month, Glasgow Outcome Score (GOS) on leaving the hospital, at 3 months, and 6 months by modified Rankin scale (mRS).
\end{abstract}

Results: Decompressive craniectomy leads to decrease in mortality rate at 30 days and acceptable GOS outcome at discharge. At 3 months and 6 months good functional outcome based on mRS occurred in cases of the infarction volume below than $250 \mathrm{ml}$, midline shift below $10 \mathrm{~mm}$, good Glasgow Coma Scale (GCS) score before surgery and rapid surgical intervention (within 24 hours).

Conclusion: Decompressive craniectomy gets great functional outcome in cases of young cases with acceptable GCS score before surgery, fair radiological pictures, and operated upon in less than 24 hours of onset.

Key Words: Malignant cerebral infarction - Decompressive craniectomy-Outcomes.

\section{Introduction}

THE incidence of malignant Middle Cerebral Artery (MCA) infarction in cases diagnosed as

Correspondence to: Dr. Mohamed A. Ghoneim, The Department of Neurosurgery, Faculty of Medicine, Cairo University ischemic stroke is up to $10 \%$ of all patients. It is defined as an infarction affecting an area including at least two thirds of that supplied by the MCA [1] Huge space-occupying infarctions with extensive edema which lead to herniation, and usually death. Extensive cerebral edema and infarcted brain tissue cause mass effect which leads to brain tissue displacement and increasing in Intracranial Pressure (ICP). Early clinical pictures include manifestation of MCA occlusion, like hemiparesis, hemiplegia, and altered consciousness [2]. Rapid deterioration occur in these patients within first 48 hours as a result of mass effect that may leads to death [3] Intensified medical treatment with mechanical and hyperventilation, hypothermia, osmotic diuretics, and sedation, not effective enough with noted mortality rates up to $80 \%$ in spite of ideal medical management [4]. Decompressive craniectomy has been recommended as a management option for huge hemispheric infarctions with cerebral edema [5]. The philosophy of the therapy is to make a space to adapt for expansion of the swollen brain, to allow normalization of intracranial pressure, avoiding brain tissue herniation, and maintaining cerebral blood flow to avoid secondary brain insult [6].Decompressive craniectomy was initially suggested as a management option for malignant MCA infarction in 1956 by Scarcella [7]. Early expert cited the poor functional outcome, moreover, the surgical complications and non resolved several points continued in early studies which included age limit, timing of surgery, the limits of satisfactory results and selection of the patients. Then the rates of death reduced significantly and functional outcome improved in cases managed by decompressive craniectomy in three randomized controlled trials, the DECIMAL [8], HAMLET [9], and DESTINY [6] key factors associated with encouraging result include younger age and rapid surgical treatment. 


\section{Patients and Methods}

Malignant MCA infarction and their mass effect diagnosed by non contrasted CT scan Fig. (1). The study included 14 patients of malignant middle cerebral artery infarctions operated upon by decompressive surgery (from January 2015 to August 2018). Pre-treatment clinical evaluation was based on the Glasgow Coma Scale (GCS). We assessed results by estimation of the rate of mortality after one month, Glasgow Outcome Score (GOS) (Table 1) on discharge, and after 3 and 6 months by modified Rankin scale (mRS) months.

\section{The Modified Rankin Scale (mRS) [10]:}

The scale runs from 0-6, running from perfect health without symptoms to death.

0 - No symptoms at all.

1- No significant disability. Able to carry out all usual activities, despite some symptoms.

2- Slight disability. Able to look after own affairs without assistance, but unable to carry out all previous activities.

3- Moderate disability. Requires some help, but able to walk without assistance.

4- Moderately severe disability. Unable to attend to own bodily needs without assistance, and unable to walk unassisted.

5- Severe disability. Requires constant nursing care and attention, bedridden, incontinent.

6- Dead.

Table (1): The Glasgow Outcome Scale (GOS) [11]

\begin{tabular}{ll}
\hline (GOS) score & Functional status \\
5 & - Good recovery: Resumption of normal life \\
& despite minor deficits. \\
4 & Moderate disability: Disabled but \\
& independent; can work in sheltered setting. \\
3 & Severe disability: Conscious but disabled; \\
& dependent on others for daily support. \\
2 & Persistent vegetative state: Minimal \\
& responsiveness. \\
\hline
\end{tabular}

Surgical treatment by decompressive craniectomy measure about $10 \mathrm{X} 12 \mathrm{~cm}$ in width Fig. (2) with duroplasty Fig. (3). Inclusion criteria include age range $18-65$ years, GCS score more than 6 , less than 48 hours from the symptoms onset to surgery, progressive decrease in the level of consciousness, CT picture of infraction in the MCA territory not less than $50 \%$, or infarct volume at least $145 \mathrm{~cm}^{3}$. We excluded patients had GCS equal or less than 6 and patient with loss of brain stem reflexes, prestroke score on the MRS $>2$, other serious illness, contralateral ischemia, or other brain pathology.

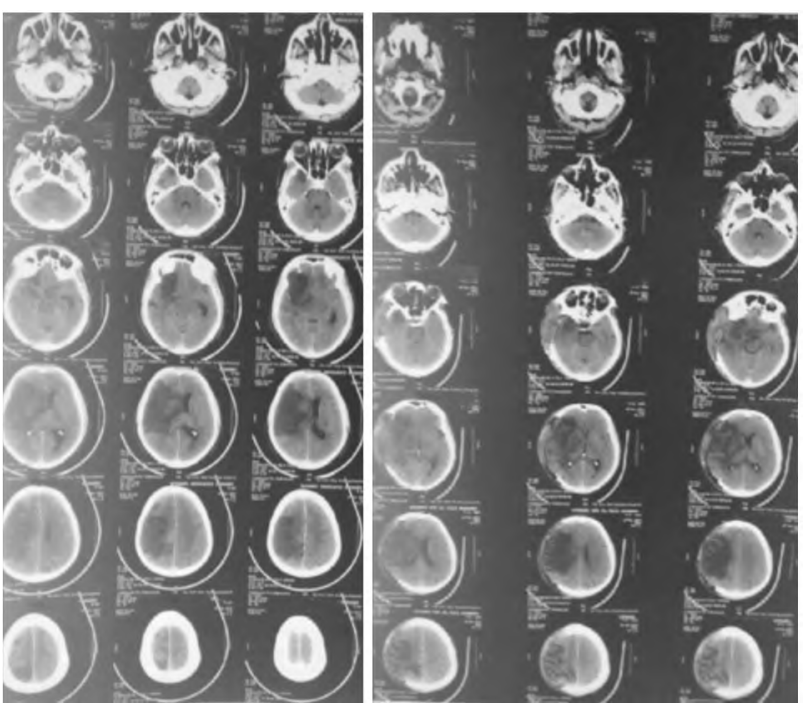

Fig. (1): (A) CT scan of right malignant middle cerebral artery infarction. B) After decompressive hemicraniectomy.

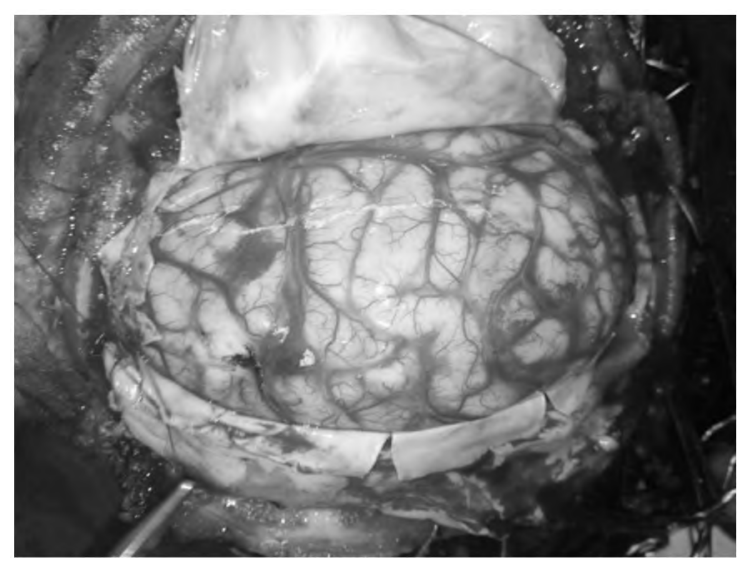

Fig. (2): Standardized decompressive craniectomy measuring $10 \times 12 \mathrm{~cm}$ in diameter.

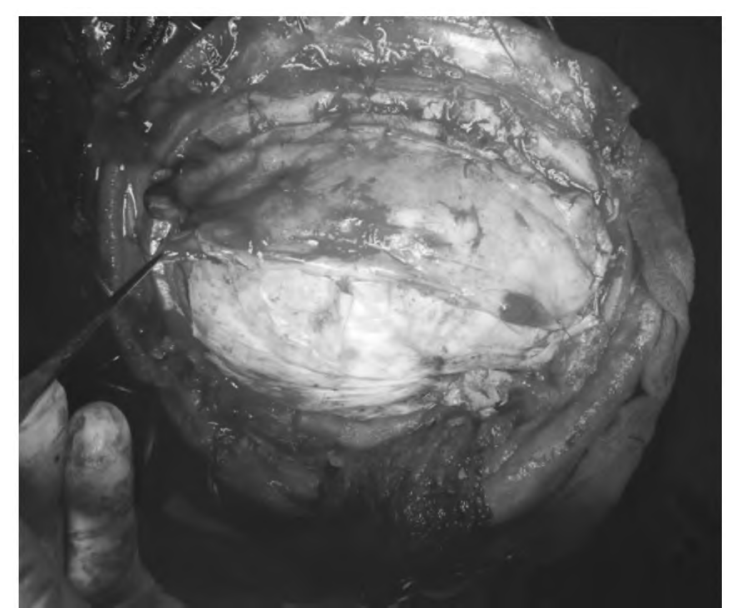

Fig. (3): Augmentation duroplasty done by pericranium. 


\section{Results}

The study included 14 patients with malignant MCA infarction during the study period. Mean age of the patients was $52.7( \pm 8.17)$ years. Ranging from 34 to 65 years, the most of patients between $46-55$ years of age $(43 \%)$. Non dominant hemisphere was involved in 6 patients $(42.9 \%)$ while dominant hemisphere affection was seen in 8 patients $(57.1 \%)$. Mean time from stroke onset to brain CT scan was 11.2 hours. Infarct volume ranged between $200 \mathrm{ml}$ and $330 \mathrm{ml}$, and was classified as either less than or exceeding $250 \mathrm{ml}$. Infarct volume exceeding $250 \mathrm{ml}$ was seen in $64.3 \%$ of the total sample (9 patients) median midline shift in this was $8.2 \mathrm{~mm}$, and a cut off of $10 \mathrm{~mm}$ was used to classify ceases. Midline shift exceeding $10 \mathrm{~mm}$ was noted in $(57 \%) 8$ of the patients.

Most of the patients (71.4\%) 10 had a GCS score of between 6 and 9 before surgery. Mean time $( \pm \mathrm{SD})$ between stroke onset and surgery was $27.3 \mathrm{~h}( \pm 8.6)$.

Mortality rate was (35.7\%) 5. Favorable outcome based on GOS at discharge (33\%) 3 from 9. Good outcome based on (mRS $<4$ ) was seen in (44.4\%) 4 patients after 3 months. (66.6\%) 6 patients after 6 months. Table (2).

Table (2): Outcome in patients with malignant MCA.

\begin{tabular}{ll}
\hline Outcome measure & \\
\hline Mortality rate at 30 days: & \\
Alive & $64.3 \%(9 / 14)$ \\
Death & $35.7 \%(5 / 14)$ \\
GOS at discharge: & \\
Unfavorable <=3 & $67 \%$ \\
Favorable 4-5 & $33 \% 3$ patients \\
mRS at 3 months: & \\
Poor outcome <=3 & $56 \%$ \\
Good outcome 4-6 & $44 \% 4$ patients \\
mRS at 6 months: & \\
Poor outcome & $33 \%$ \\
Good outcome & $67 \% 6$ patients \\
\hline
\end{tabular}

\section{Discussion}

The outcome of the patients after 6 month of surgery had a significant affection with preoperative GCS score, the GCS score was used as the primary tool of evaluation in this study. Consistent with the findings from previously published papers, the GCS score is accurate in predicting outcome of the patients with malignant MCA territory infarction. GCS score has a strong predictive value for outcome, good functional outcome was obtained in cases with GCS 10-13 before surgery at 6 months $(90.9 \%)$, in contrast to those with GCS score 6-9 before surgery (45.6\%) [12]. In our study pre-op. GCS 10-13 had a good functional outcome in $75 \%$ poor in $25 \%$ and GCS 6-9 had a good functional outcome in $30 \%$ poor in $70 \%$. Good functional outcome after 6 months was obtained in patients aged 56-65 years and operated upon by decompressive craniectomy $(64.4 \%$ good outcome), in contrast to cases managed medically (25\% good outcome), this indicate the advantage of decompressive craniectomy this age group $[13,14]$. In our study good functional outcome at 6 months was obtained in $(66.6 \%)$ of cases younger than 56 years. Results from $[\mathbf{5 , 6 , 9 ]}$ showed that outcome form dominant hemisphere involvement was unfavorable comparable with that from non dominant hemispheric infarction similar findings were noted in this study. Poor outcome at 6 months obtained in cases infarct volume more than $250 \mathrm{ml}$ and managed surgically [15] similar findings were noted in our study infarction volume of less than 250 had a GOOD result in $80 \%$ and poor result in $20 \%$ infarct volume of more than 250 had a good result in $22 \%$ poor in $78 \%$. Midline shift more than $10 \mathrm{~mm}$ associated with bad outcome at 6 months [15] similar findings were noted in our study midline shift less than $10 \mathrm{MM}$ good result in $83 \%$, poor in $17 \%$ midline shift more than $10 \mathrm{MM}$ good result in $12.5 \%$ poor in $87.5 \%$ (Table 3 ).

Table (3): Factors influencing outcome at 6 months.

\begin{tabular}{|c|c|c|c|}
\hline Factors & $\mathrm{N}$ & $\begin{array}{c}\text { Good outcome } \\
6 \mathrm{M}\end{array}$ & $\begin{array}{c}\text { Poor outcome } \\
6 \mathrm{M}\end{array}$ \\
\hline \multicolumn{4}{|l|}{ Age: } \\
\hline$<56$ & 6 & $66 \%(4 / 6)$ & $33 \%(2 / 6)$ \\
\hline$>56$ & 8 & $25 \%(2 / 8)$ & $75 \%(6 / 8)$ \\
\hline \multicolumn{4}{|c|}{ Site infarction: } \\
\hline LT & 8 & $37.5 \%(3 / 8)$ & $62.5 \%(5 / 8)$ \\
\hline RT & 6 & $50 \% \quad(3 / 6)$ & $50 \% \quad(3 / 6)$ \\
\hline \multicolumn{4}{|l|}{ Volume: } \\
\hline$<250$ & 5 & $80 \% \quad(4 / 5)$ & $20 \% \quad(1 / 5)$ \\
\hline$>250$ & 9 & $22.2 \%(2 / 9)$ & $77.8 \%(7 / 9)$ \\
\hline \multicolumn{4}{|c|}{ Midline shift: } \\
\hline$<10$ & 6 & $83.3 \%(5 / 6)$ & $16.7 \%(1 / 6)$ \\
\hline$>10$ & 8 & $12.5 \%(1 / 8)$ & $87.5 \%(7 / 8)$ \\
\hline \multicolumn{4}{|c|}{ Pre-op. GCS: } \\
\hline 10-13 & 4 & $75 \%(3 / 4)$ & $25 \%(1 / 4)$ \\
\hline $6-9$ & 10 & $30 \%(3 / 10)$ & $70 \%(7 / 10)$ \\
\hline \multicolumn{4}{|c|}{ Surgery interval: } \\
\hline$<24 \mathrm{~h}$ & 5 & $80 \% \quad(4 / 5)$ & $20 \% \quad(1 / 5)$ \\
\hline$>24 h$ & 9 & $22.2 \%(2 / 9)$ & $77.8 \%(7 / 9)$ \\
\hline
\end{tabular}

\section{Conclusion:}

Decompressive craniectomy gets great functional outcome in cases of young casess with acceptable GCS score before surgery, fair radiological 
pictures, and operated upon in less than 24 hours of onset.

\section{References}

1- HACKE W., SCHWAB S., HORN M., SPRANGER M., De GEORGIA M. and VON KUMMER R.: Malignant middle cerebral artery territory infarction: Clinical course and prognostic signs. Arch. Neurol., 53: 309-15, 1996.

2- DEMCHUK A.M. and KRIEGER D.W.: Mass effect with cerebral infarction. Curr. Treat. Options. Neurol., 1: 18999, 1999.

3- QURESHI A.I., SUAREZ J.I., YAHIA A.M., MOHAMMADY, UZUN G., SURI M.F., et al.: Timing of neurologic deterioration in massive middle cerebral artery infarction: A multicenter review. J. Crit. Care Med., 31: 272-7, 2003.

4- CHEUNG A., TELAGHANI C.K., WANG J., YANG Q., MOSHER T.J., REICHWEIN R.K., et al.: Neurological recovery after decompressive craniectomy for massive ischemic stroke. Neurocrit. Care, 3: 216-23, 2005.

5- VAHEDI K., VICAUT E., MATEO J., KURTZ A., ORABI M., GUICHARD J.P., et al.: Sequentialdesign, multicenter, randomized, controlled trial of early decompressive craniectomy in malignant middle cerebral artery infarction (DECIMAL Trial). Stroke, 38: 2506-17, 2007.

6- JUTTLER E., SCHWAB S., SCHMIEDEK P., UNTERBERG A., HENNERICI M., WOITZIK J., et al.: Decompressive surgery for the treatment of malignant infarction of the middle cerebral artery (DESTINY): A randomized controlled trial. Stroke, 38: 2518-25, 2007.

7- BERROUSCHOT J., STERKER M., BETTIN S., KOSTER J. and SCHNEIDER D.: Mortality of space occupying (malignant) middle cerebral artery infarction under conservative intensive care. Int. Care Med., 24: 620-3, 1998.
8- HOFMEIJER J., VAN DER WORP H.B. and KAPPELLE L.J.: Treatment of space occupying cerebral infarction. Crit. Care Med., 31: 617-25, 2003.

9- HOFMEIJER J., KAPPELLE L.J., ALGRA A., AMELINK G.J., VAN GIJN J. and VAN DER WORP H.B.: HAMLET investigators. Surgical decompression for space occupying cerebral infarction the Hemicraniectomy after middle cerebral arterial infarction with life threatening edema trial (HAMLET): A multicentre, open, randomised trial. Lancet Neurol., 8: 326-33, 2009.

10- BONITA R. and BEAGLEHOLE R.: "Modification of Rankin Scale: Recovery of motor function after stroke." Stroke, Dec.; 19 (12): 1497-500, 1988.

11- JENNETT B. and BOND M.: Assessment of outcome after severe brain damage. Lancet, Mar. 1, 1 (7905): 4804, 1975.

12- WEIR C.J., BRADFORD A.P. and LEES K.R.: The prognostic value of the components of the Glasgow Coma Scale following acute stroke. Q.J.M., 96: 67-74, 2003.

13- YAO Y., LIU W., YANG X., HU W. and LI G.: Is decompressive craniectomy for malignant middle cerebral artery infarction of any benefit for elderly patients. Surg. Neurol., 64: 165-9, 2005.

14- YU J.W., CHOI J.H., KIM D.H., CHA J.K. and HUH J.T.: Outcome following decompressive craniectomy for patients older than 70 years old. J. Cerebrovasc. Endovasc. Neurosurg., 14: 65-74, 2012.

15- MORI K., NAKAO Y., YAMAMOTO T. and MAEDA M.: Early external decompressive craniectomy with duroplasty improves functional recovery in patients with massive hemispheric embolic infarction; Timing and indications for surgery. Surg. Neurol., 62: 420-30, 2004.

\section{قطع القحف لعلاج جلطات الهخ

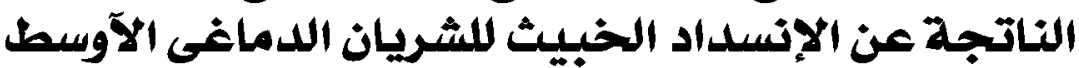

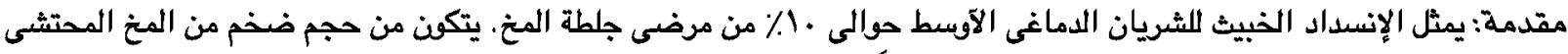

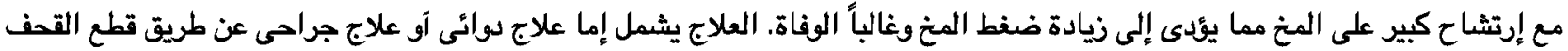

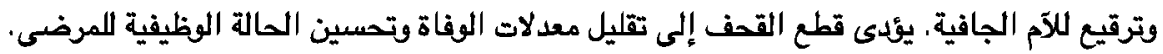

